\title{
Efficiency Improvement of PV Generation System by Using Improved P \& O Method of MPPT
}

\author{
Chengyang Huang ${ }^{1}$, Kazutaka Itako ${ }^{1}$, Takeaki Mori ${ }^{1}$ and Qiang $\mathrm{Ge}^{2}$ \\ 1. Department of Electrical and Electronic Engineering, Kanagawa Institute of Technology, Kanagawa 243-0292, Japan \\ 2. Department of Energy and Power Engineering, Yangzhou University, Yangzhou 225127, China
}

Received: January 07, 2015 / Accepted: March 02, 2015 / Published: May 31, 2015.

\begin{abstract}
The conventional P \& O (perturb-and-observe) method, which is the most widely used as MPPT (maximum power point tracking) control, has the problem of low efficiency and unstable operation when solar radiation changes drastically. Aiming at this problem, this paper improves the conventional P \& O method to reduce the bad effect of solar radiation by shortening the sampling interval of PV module's output power while keeping the operating period unchanged. Experiments are conducted to study efficiency gains of improved method when solar radiation changes drastically. The result shows that, by this method, the efficiency of MPPT control can be increased $17 \%$ in average when PV module simulator is used and $20 \%$ at maximum when actual PV module is used, compared with the conventional P \& O method.
\end{abstract}

Key words: PV generation system, MPPT, solar radiation change, improvement of efficiency.

\section{Introduction}

Nowadays in a household PV generation system, the $\mathrm{P} \& \mathrm{O}$ (perturb-and-observe) method is the most widely used as MPPT (maximum power point tracking) control. However, it has several problems in actual application. So, Itako, et al. [1-4] have discussed the improved MPPT control method. One of the problems of conventional $\mathrm{P} \& \mathrm{O}$ method is low efficiency and unstable operation when solar radiation changes drastically. To solve this problem, we have proposed an improved $\mathrm{P} \& \mathrm{O}$ method which has different sampling timing and same operating period with the conventional $\mathrm{P} \& \mathrm{O}$ method. The result of experiments shows that, by the new method, the efficiency of MPPT method can be increased when solar radiation changes drastically.

\section{The Problem of the Conventional Method}

The $\mathrm{P} \& \mathrm{O}$ method is the most widely used as MPPT control. It is executed by periodically

Corresponding author: Kazutaka Itako, Dr., professor, research field: power electronics. E-mail: itako@ele.kanagawa-it.ac.jp. perturbing (incrementing or decrementing) the array terminal voltage and comparing the PV output power with that of the previous perturbation cycle. If the power is increasing, the perturbation will continue in the same direction in the next cycle, otherwise, the perturbation direction will be reversed [5-8]. The flowchart of this method is represented in Fig. 1.

However, the conventional P \& O method can lead to the problem of low efficiency when solar radiation changes drastically. Fig. 2 shows the operation of the conventional method when solar radiation is stable. Fig. 2a demonstrates the waveform of the PV module's output voltage. Assuming that the voltage is perturbed from $V_{1}$ to $V_{2}$, as the sampling period of the conventional method is the same as the operating period, the output power of PV module is sampled at $t_{1}$ and $t_{2}$ (sampling interval $\Delta t$ ), and then, $P_{1}$ and $P_{2}$ will be compared for the next move. Fig. $2 b$ is PV characteristics of the module that correspond to timing $t_{1}$ and $t_{2}$. According to the principle of the $\mathrm{P} \& \mathrm{O}$ method, the output voltage will be moved back to $V_{1}$ when $P_{1}>P_{2}$ is determined. 


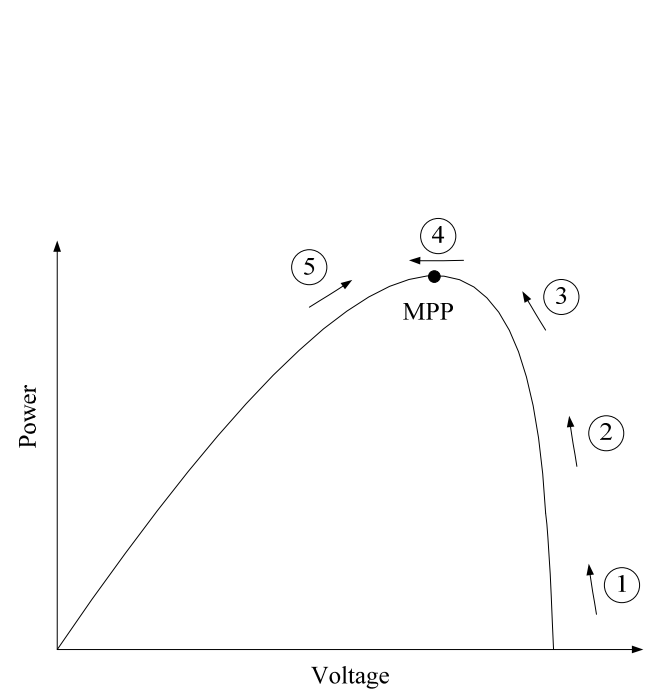

(a)

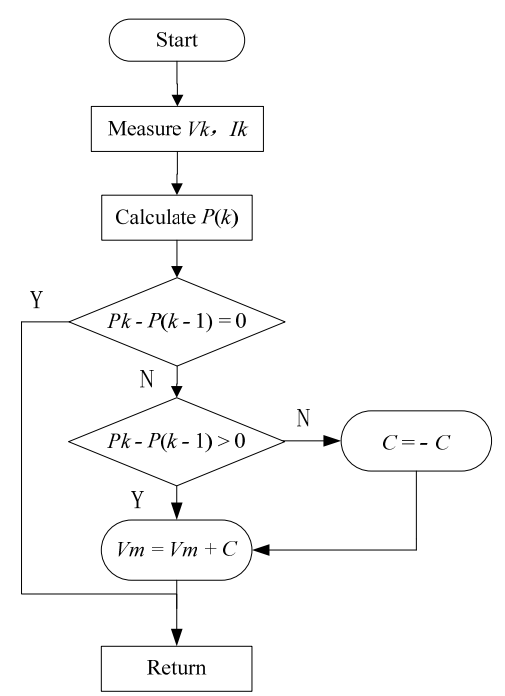

(b)

Fig. 1 The flowchart of P \& $O$ method.

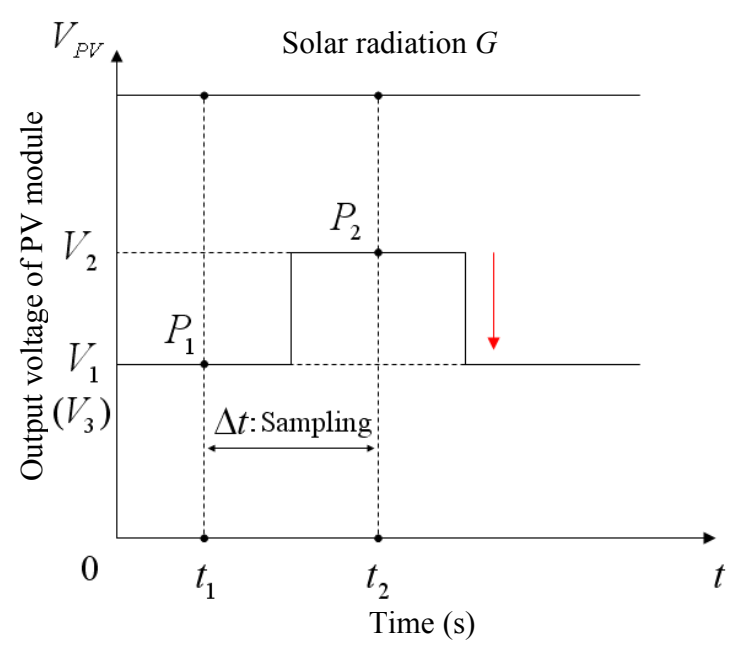

(a) The waveform of output voltage

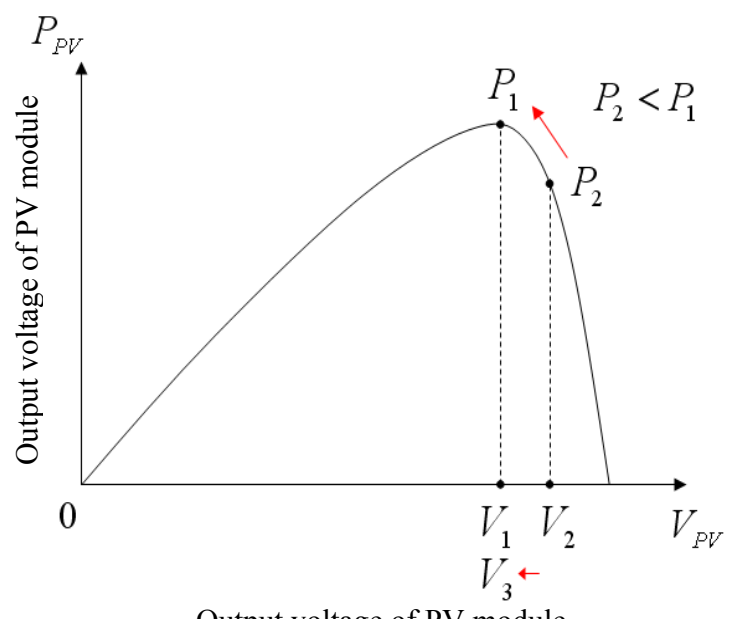

Output voltage of PV module

(b) $\mathrm{P}-\mathrm{V}$ characteristic

Fig. 2 The operation of the conventional method (stable solar radiation).

Fig. 3 shows the operation of the conventional method when solar radiation is rising. As shown in Fig. $2 \mathrm{~b}$, it should be $P_{1}>P_{2}$ when operating point is altered from $V_{1}$ to $V_{2}$. But, by the effect of the increasing solar radiation, $\mathrm{P}-\mathrm{V}$ characteristic is changed from $\mathrm{P}-\mathrm{V}_{t 1}$ to $\mathrm{P}-\mathrm{V}_{t 1}$ in Fig. $3 \mathrm{~b}$. As a result, the judgment of $P_{1}<P_{2}$ is made, the operating point is incorrectly moved to $V_{3}$, which away from the MPP (maximum power point).

As shown in Fig. 4, if the solar radiation continues to rise, the operating point will become unstable and gradually move away from the MPP, leading to a low efficiency of the system.

\section{The Improved Method}

The variation $\mathrm{d} P$ of module's output power that based on the operating of the P \& O method can be explained by Eq. (1):

$$
\begin{gathered}
\mathrm{d} P=P\left(t_{2}\right)-P\left(t_{1}\right)=\mathrm{d} P_{\Delta v}+\mathrm{d} P_{\Delta G}(\Delta t) \\
\lim _{\Delta t \rightarrow 0} \mathrm{~d} P=\mathrm{d} P_{\Delta v}+0
\end{gathered}
$$

It can be seen that, the influence of the solar radiation can be restrained by shortening $\Delta t$. The most obvious way would be shortening the operating period 


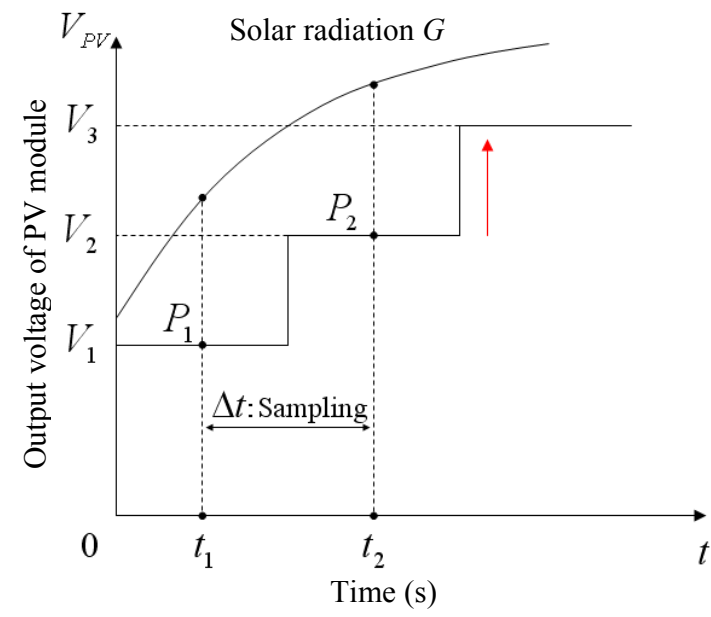

(a) The waveform of output voltage

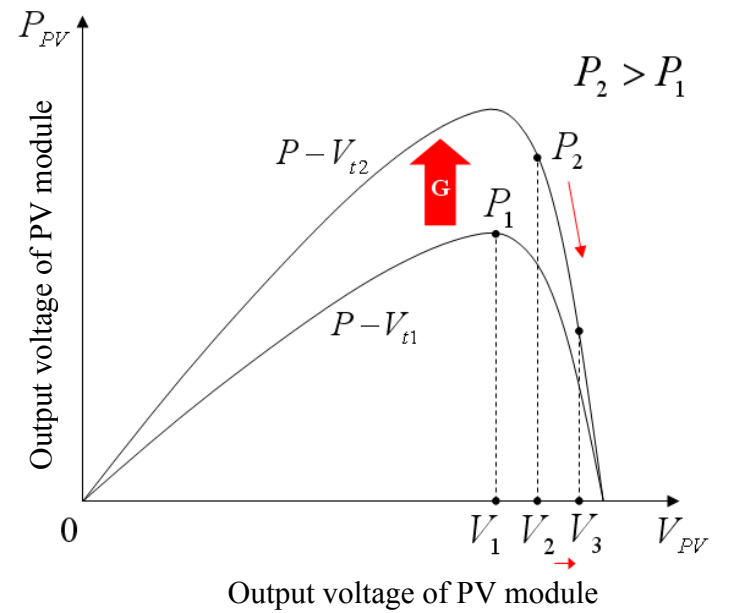

(b) P-V characteristic

Fig. 3 The operation of the conventional method (increasing solar radiation).

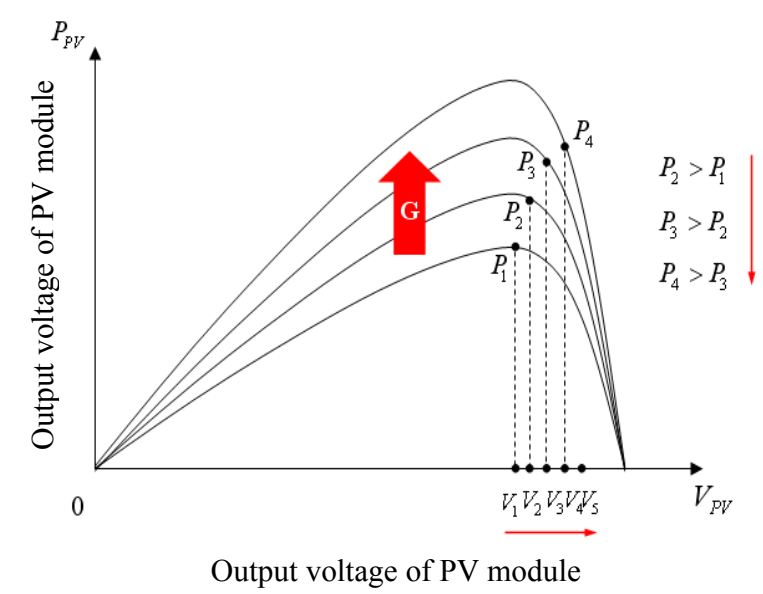

Fig. 4 The operation when solar radiation continues to grow.

of the P \& O method. However, to achieve this goal, the hardware (for example, the dynamic characteristics of the circuit) has to be reconsidered for the high-frequency PWM (pulse width modulation) signal. There is also a possibility of unstable output if the operating period is too short.

As shown in Fig. 5a, this paper proposed an improved method that taking the sampling timing immediately before and after the alteration of voltage. By this way, $\Delta t$ is greatly shortened, the PV characteristics in Fig. 5b that corresponding to timing $t_{1}$ and $t_{2}$ will be basically the same, virtually unaffected by the increasing solar radiation. Therefore, $P_{1}>P_{2}$ is accurately judged, the low efficiency caused by solar radiation can be suppressed. In this method, because the operating period is unchanged, no changing of hardware is required.

\section{Experiments}

The control system of experiments is shown in Fig. 6. It is composed of a boost converter which operating MPPT control to the PV array.

The conventional method and the improved method will be compared in the experiments. The setting parameters of two methods are shown in Table 1. The parameters of conventional method are set according to the commercial products. The operating period and perturbing voltage of two methods are the same while the sampling interval $\Delta t$ of improved method is quite shortened.

\subsection{The Experiment Using Simulator of PV Module}

The simulator of PV module which can set the changing solar radiation freely is first taken for the experiment. The variation of solar radiation is set as following rule: increasing the solar radiation level from $30 \%$ to $100 \%$ (Equivalent to $1,000 \mathrm{~W} / \mathrm{m}^{2}$ ) in $8 \mathrm{~s}$ and then reducing from $100 \%$ to $30 \%$ in 8 s repeatedly. Fig. 7a shows the waveform of conventional method. It can be seen that, the output voltage of PV module simulator is very unstable and changing sharply as the 


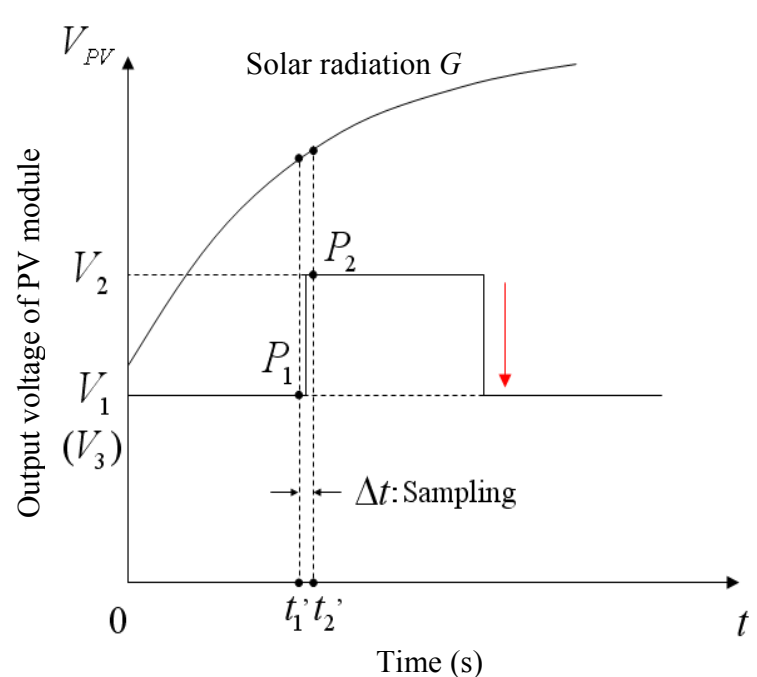

(a) The waveform of output voltage

Fig. 5 The operation of the improved method.

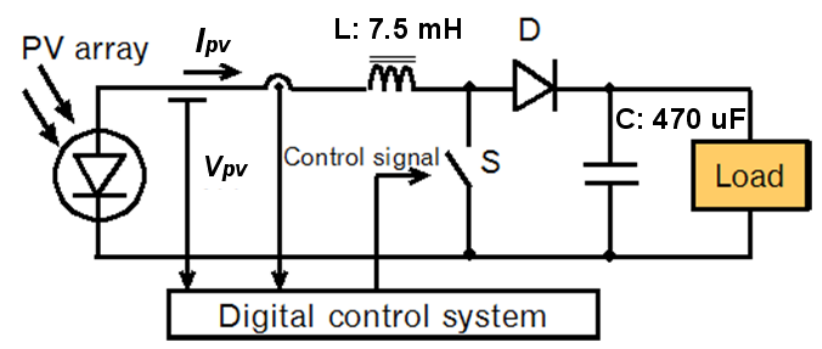

Fig. 6 The control system of experiments.

Table 1 The setting parameters of MPPT control.

\begin{tabular}{lll}
\hline & $\begin{array}{l}\text { Conventional } \\
\text { method }\end{array}$ & $\begin{array}{l}\text { Improved } \\
\text { method }\end{array}$ \\
\hline Operating period $(\mathrm{s})$ & 1 & 1 \\
Sampling interval $\Delta t(\mathrm{~s})$ & 1 & 0.15 \\
Perturbing voltage $(\mathrm{V})$ & 1 & 1 \\
\hline
\end{tabular}

solar radiation. Fig. $7 \mathrm{~b}$ shows the waveform of improved method. As the solar radiation changing drastically, the output voltage is operating stably.

Fig. 8 shows the MPPT efficiency (= the output power of PV module simulator $P_{P V} / P_{\max } \times 100 \%$ ) of two methods. The average MPPT efficiency of the conventional method is $72.2 \%$ while the improved method is $90 \%, 17 \%$ increased by comparison. Therefore, it is confirmed that, the MPPT efficiency of improved method is greatly increased compared with conventional method.

\subsection{The Experiment Using Actual PV Module}

The experiment using actual PV module is also

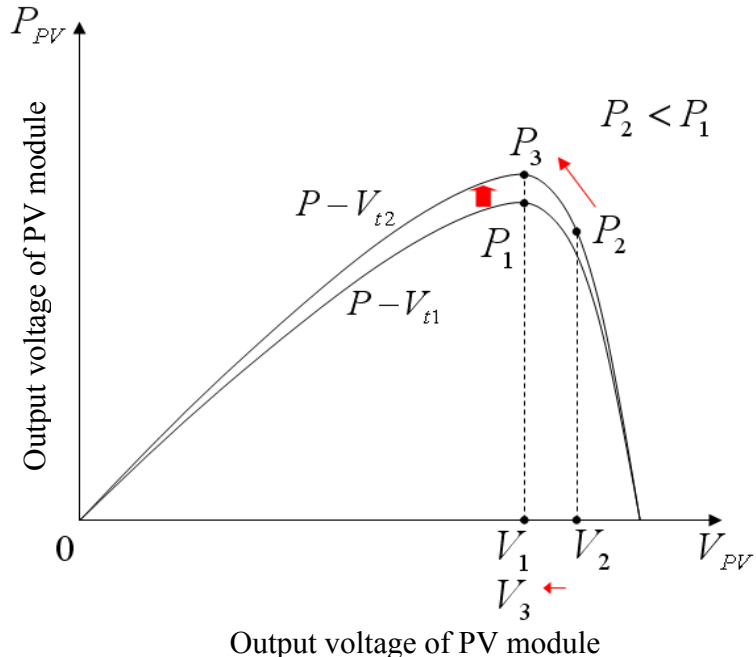

(b) P-V characteristic

conducted. The picture of the control system is shown in Fig. 9, it has same structure with Fig. 6. Table 2 shows the electronic parameters of $\mathrm{PV}$ module.

Fig. 10 shows the operation of two methods in the condition of actual solar radiation. When solar radiation suddenly increases, the output voltage of the improved method continues to operating at the MPP stably and the output power is also increased at the growth rates of solar radiation. On the contrary, the output voltage of the conventional method becomes unstable and moves away from the MPP as the solar radiation is rising. The output power of the improved method increases about $20 \%$ at maximum compared with conventional method after calculation.

\section{Conclusions}

This paper proposes an improved $\mathrm{P} \& \mathrm{O}$ method which shortens sampling interval of PV module's output power to inhibit the influence of changing solar radiation. In the experiment using simulator of PV module, the MPPT efficiency is increased $17 \%$ in average by improved method. In the experiment of actual PV module, efficiency can be increased $20 \%$ at maximum compared with conventional method. Therefore, it is confirmed that, the improved method can solve the problem of low efficiency caused by the rapid change of solar radiation. 


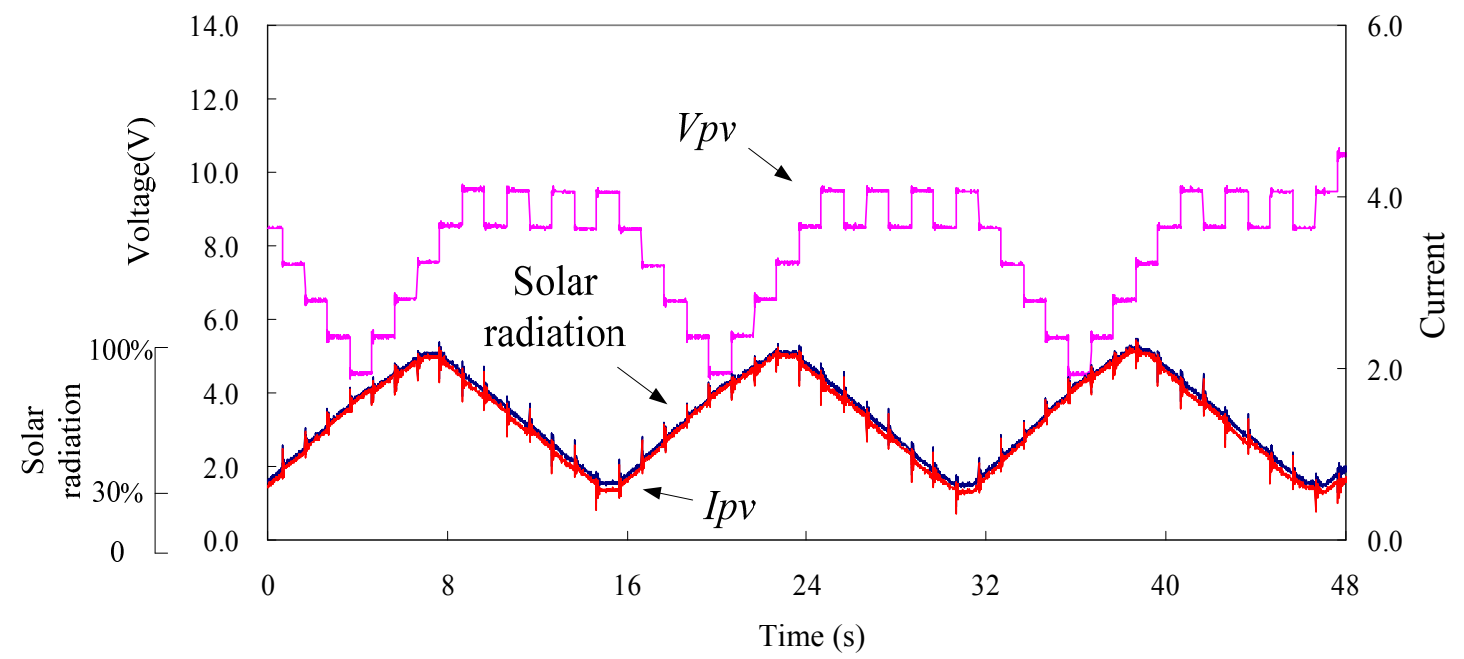

(a) The conventional method

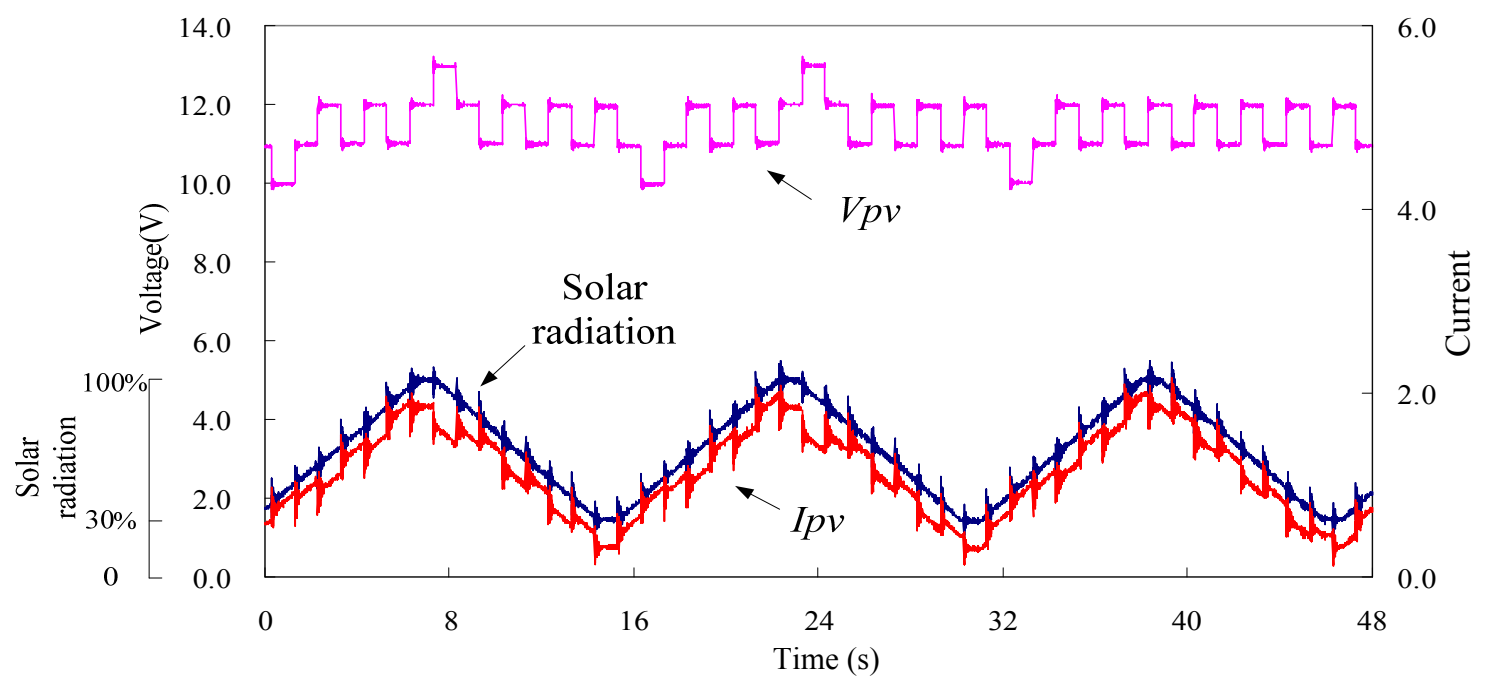

(b) The improved method

Fig. 7 The operation waveform under the changing solar radiation.

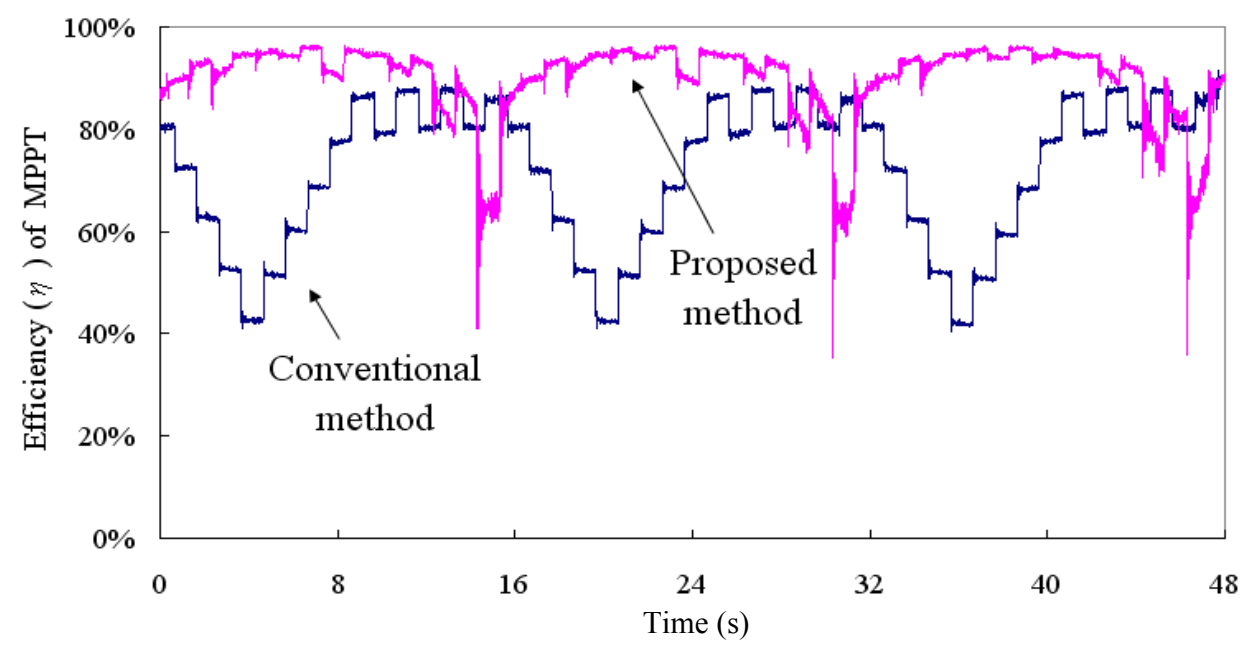

Fig. 8 The efficiency of two methods. 


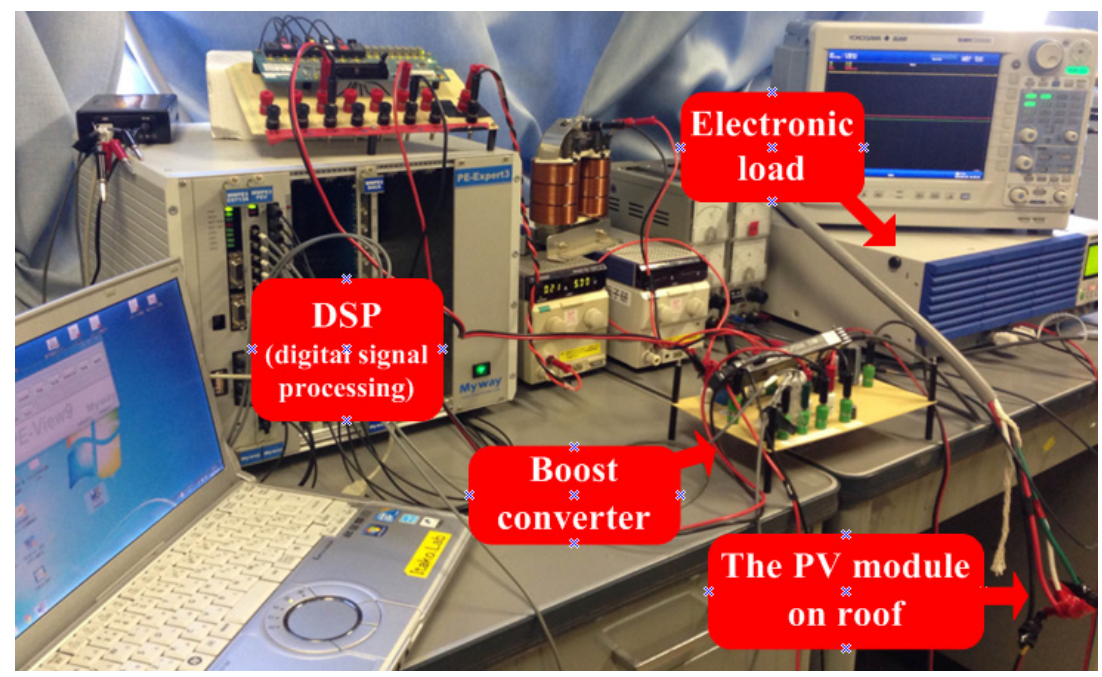

Fig. 9 The picture of the control system.

Table 2 The electronic parameters of PV module.

\begin{tabular}{lll}
\hline Maximum power $(\mathrm{W})$ & Maximum power voltage $(\mathrm{V})$ & Maximum power current $(\mathrm{A})$ \\
\hline 50 & 16.4 & 3.05 \\
\hline
\end{tabular}

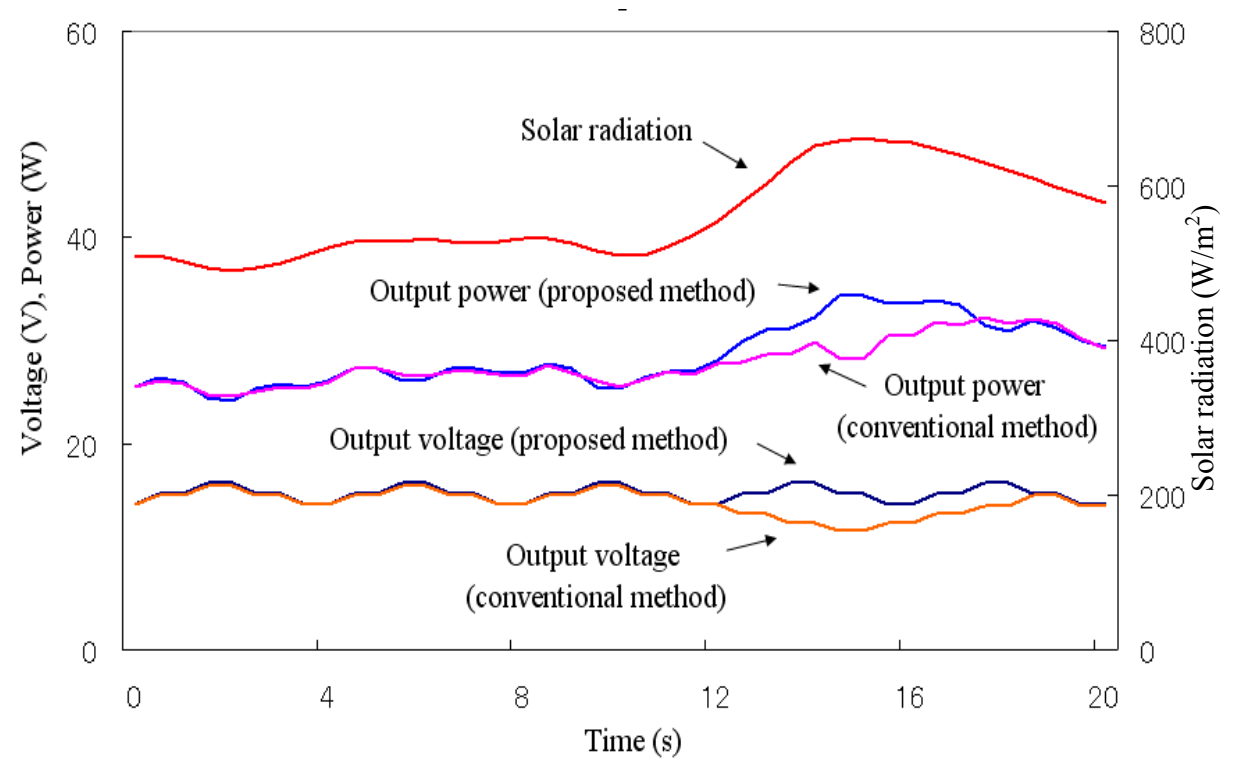

Fig. 10 The operation of MPPT control.

Since the improved method has not been tested in an actual PV generation system $(5 \mathrm{~kW})$, the experiments on actual system are future work.

\section{References}

[1] Itako, K., and Mori, T. 2006. "A New MPPT Control Method for PV Generation Systems." Presented at the International Conference on Electrical Engineering, Kunming, China.

[2] Itako, K. 2012. "A Detecting Interval Control in MPPT
Control with I-V Characteristics Scanning for a PV Generation System." Presented at the International Conference on Electrical Engineering, Kanazawa, Japan.

[3] Itako, K. 2013. "New I-V Characteristics Scan-Type MPPT Control Method for PV Generation System." Journal of Technology Innovations in Renewable Energy 1 (2): 87-91.

[4] Itako, K. 2014. "High Efficiency PCS with Scan-Type MPPT Control for a Grid-Connected PV Power Generation System." Journal of Energy and Power Engineering 8 (1): 137-43. 
[5] Subudhi, B., and Raseswari. P. 2013. "A Comparative Study on Maximum Power Point Tracking Techniques for Photovoltaic Power Systems." IEEE Transactions on Sustainable Energy 4 (1): 89-98.

[6] Hua, C., Lin, J., and Shen, C. 1998. "Implementation of a DSP-Controlled Photovoltaic System with Peak Power Tracking." IEEE Trans. Ind. Electron. 45 (1): 99-107.
[7] Koutroulis, E., Kalaitzakis, K., and Voulgaris, N. C. 2001. "Development of a Microcontroller-Based Photovoltaic Maximum Power Point Tracking Control System." IEEE Trans. Power Electron. 16 (1): 46-54.

[8] Femia, N., Petrone, G., Spagnuolo, G., and Vitelli, M. 2005. "Optimization of Perturb and Observe Maximum Power Point Tracking Method." IEEE Trans. Power Electronics 20 (4): 963-73. 